Universidade Tecnológica Federal do Paraná - UTFPR

Campus Ponta Grossa - Paraná - Brasil

ISSN: 1981-3686 / v. 03, n. 01: p. 01-14, 2009
Revista Brasileira de Tecnologia

Agroindustrial

\title{
EFEITO DA ADIÇÃO DE AMÊNDOAS DA CASTANHA DE CAJU NAS PROPRIEDADES SENSORIAIS DO IOGURTE ADOÇADO COM MEL
}

\section{EFFECT ADDITION OF ALMONDS THE CASHEW NUT IN SENSORY PROPERTIES OF YOGHURT SWEETENED WITH HONEY}

\author{
Jéfferson Malveira Cavalcante ${ }^{1}$; Ana Cristina da Silva Morais ${ }^{1}$; Maria do Carmo Passos Rodrigues ${ }^{1}$ \\ ${ }^{1}$ Universidade Federal do Ceará - UFC - Fortaleza - Brasil jmalveirac@gmail.com
}

\begin{abstract}
Resumo
O iogurte é um produto resultante da fermentação do leite pasteurizado, por fermentos lácticos. Nos últimos anos, a indústria de alimentos tem lançado diversos produtos para conquistar mercado, principalmente devido às alterações nas preferências dos consumidores. Desse modo, o estudo tem como objetivo desenvolver e avaliar as propriedades sensoriais de três protótipos de iogurte natural adoçado (INA) com mel sabor castanha (decodificados em 1, 2 e 3), diferenciados em relação ao tempo de mistura da amêndoa da castanha de caju com o iogurte. As matériasprimas comerciais utilizadas foram: INA com 1\% de mel e amêndoas da castanha de caju em pedaços. Uma escala estruturada de cinco pontos foi utilizada para avaliação da atitude de compra $e$ três escalas de nove pontos: uma de escala hedônica, uma para análise de diferença do controle $e$ outra para avaliar a atitude de consumo. Participaram dos testes 40 provadores não treinados. A amostra 1 apresentou um elevado potencial de compra, de consumo, foi a mais preferida em aparência, aceitação global, aroma, sabor e textura, enquanto que a amostra 3 teve a textura e a granulosidade como características menos preferidas, mostrando que uma textura mais homogênea têm maior aceitação pelos consumidores. Já no atributo cor, a amostra de maior preferência foi a 2. O teste de diferença do controle mostrou que as amostras adicionadas de castanha de caju diferiram $(p \leq 0,05)$ em termos globais da amostra controle. Portanto, o iogurte adoçado com mel sabor castanha, possivelmente, ocuparia um bom espaço no mercado.
\end{abstract}

Palavras-chave: iogurte; amêndoas de castanha de caju; análise sensorial.

\section{Introdução}

O iogurte é um produto resultante da fermentação do leite pasteurizado ou esterilizado, por fermentos lácticos próprios (BRASIL, 2000; SILVA, 2000). Por apresentar um gosto ácido (pH 3,8), o iogurte é disfarçado quando são acrescentados outros ingredientes naturais. Na prática as frutas utilizadas são muito variadas e refletem os gostos dos consumidores desde os clássicos iogurtes de morango e de banana até os mais exóticos de maçã com caramelo, frutas silvestres, etc (ORDONEZ, 2005; TAMIME \& ROBINSON, 2000). 
Segundo Chitarra \& Chitarra (2005) a castanha de caju, fruto verdadeiro, é um aquênio em forma de rim com 2,5 a 3,0 cm de largura, de coloração marrom-acizentado e com um pericarpo duro desevolvido a apartir do pedicelo intusmecido. A amêndoa da castanha de caju apresenta grande valor nutritivo. É considerada fonte de proteína de alta qualidade, rica em ácidos graxos poliinsaturados e altamente energéticos, rica em gorduras e carboidratos, apresentando ainda elevados teores de cálcio, ferro e fósforo (CAJUCULTURA, 2009).

A análise sensorial compreende-se como uma ferramenta na indústria de alimentos, pois contribui no desenvolvimento de novos produtos, controle de qualidade, reformulação e redução de custos de produtos, relações entre condições de processos, ingredientes, aspectos analíticos e organolépticos. A qualidade sensorial do alimento é o resultado da interação entre o alimento e o homem. Medidas instrumentais são úteis apenas quando apresentam boa correlação com as medidas sensoriais (DUTCOSKY, 2007).

Cuidar da qualidade há muito tempo deixou de ser fator diferenciador e passou a ser um requisito indispensável para se participar do mercado (PEINADO \& GRAEML, 2007). No desenvolvimento de novos produtos a indústria de alimentos permiti a constante renovação e sustentação da imagem inovadora e promissora que as empresas pretendem construir no mercado em que atuam sendo esta uma atividade fundamental para sua sobrevivência.

Nos últimos anos, no Brasil, a indústria de alimentos tem lançado diversos produtos para conquistar mercado, principalmente devido às alterações nas preferências dos consumidores, pois a qualidade de produtos tem se tornado um importante fator de decisão na maioria dos negócios (MONTGOMERY \& RUNGER, 2003).

Desse modo, o presente trabalho teve como objetivo desenvolver e avaliar as propriedades sensoriais de três protótipos de iogurte adoçado com mel sabor castanha diferenciados em relação ao tempo de mistura da amêndoa da castanha de caju.

\section{Material e Métodos}

\subsection{Material}

Foram utilizadas amostras de iogurte de castanha, produzidas a partir de $1000 \mathrm{~g}$ de iogurte natural adoçado com $1 \%$ de mel e foi acrescentado, aproximadamente, $410 \mathrm{~g}$ de amêndoa da castanha de caju em pedaços. Houve variação entre as amostras no tempo em que foram batidas utilizando-se um liquidificador. Para designar as amostras foram adotados os números 1 (batido por 2 minutos), 2 (batido por 1 minuto) e 3 (batido por $1 / 2$ minuto). Em seguida, as amostras foram acondicionadas em garrafas de plástico de $1000 \mathrm{~mL}$, de cor branca e com tampa, mantidas sob refrigeração. 


\subsection{Métodos}

Para a caracterização da equipe, na ficha de avaliação havia um questionário de coleta de dados de faixa etária, sexo, escolaridade, hábitos de consumo referentes ao produto base e saúde do julgador. Os testes foram realizados no Laboratório de Análise Sensorial do Departamento de Tecnologia de Alimentos - DETAL na UFC, com 40 provadores: graduados, alunos de graduação e ensino médio. As amostras foram servidas, nas cabines individuais iluminadas com luz branca, à temperatura de refrigeração em recipiente codificado com três dígitos casualizados. Foi fornecida água para fazer o branco entre as amostras.

\subsubsection{Teste de escala hedônica}

Empregou-se delineamento de blocos completos e a ordem de apresentação das amostras foi aleatorizada dentro da sessão. Cada provador avaliou três amostras, de forma monádica, em uma única sessão. Utilizou-se uma escala hedônica estruturada mista de nove pontos $(1=$ desgostei extremamente, $5=$ nem gostei nem desgostei, $9=$ gostei extremamente) para que cada provador avaliasse o quanto gostou ou desgostou das amostras em relação à aparência, cor, aceitação global, aroma, sabor e textura. Os resultados da aceitação foram avaliados através de histogramas de frequencia, análise de variância (ANOVA) e teste de médias Tukey $(\mathrm{p} \leq 0,05)$.

\subsubsection{Teste de diferença do controle}

Foram utilizados provadores não-treinados que avaliaram a diferença global entre cada amostra (iogurte adoçado sabor castanha) e a amostra-controle (iogurte natural adoçado) de acordo com o teste de "Diferença do Controle" (MEILGARD, 1999). Foi empregado delineamento de blocos completos balanceados. As amostras de iogurte e a amostra-controle foram apresentadas codificadas com algarismos de três dígitos e servidas à temperatura de refrigeração, juntamente com uma amostra-padrão identificada com a letra P. Foi solicitada, aos provadores, a atribuição de notas a cada amostra segundo o grau de diferença global em relação ao controle, utilizando escala apropriada. Os resultados foram expressos como média da diferença em relação ao controle.

\subsubsection{Atitude de compra e de consumo e atributos mais e menos preferidos}

As amostras foram apresentadas de forma seqüencial, monádica e delineada em blocos completos. Foi utilizada uma escala estruturada mista de cinco pontos $(1=$ eu certamente não compraria, 3 = tenho dúvida se compraria, $5=$ eu certamente compraria) para que cada provador avaliasse a atitude de compra e uma outra escala estruturada mista de nove pontos $(1=$ comeria se fosse forçado, 5 = comeria se estivesse acessível, mas não me esforçaria para isso, $9=$ comeria 
sempre que tivesse oportunidade) para a avaliação da atitude de consumo. Cada provador avaliou três amostras em uma única sessão constatando atributos mais e menos preferidos.

\section{Resultados e Discussão}

\subsection{Caracterização dos provadores}

Foram empregados 40 provadores, 17 homens e 23 mulheres, dos quais 92,5\% eram alunos da graduação e graduados, $5 \%$ alunos de ensino médio e 2,5\% não respondentes. A maioria dos provadores era jovem, 79,4\% estavam na faixa 20-25 anos, que possui alto potencial de consumo.

Todos os julgadores relataram que gostavam de iogurte e de castanha. Com relação à freqüência de consumo, 46,1\% consumia moderadamente iogurte. Sendo assim, a maioria dos julgadores possui um grau relevante de familiaridade com o produto testado (iogurte), podendo avaliar melhor a influência da castanha nas características sensoriais do produto (Figura 1).

FIGURA 1 - Histograma de freqüência de consumo de iogurte reportada pelos provadores (freqüentemente: todo dia, moderadamente: algumas vezes por semana, ocasionalmente: quinzenalmente, raramente: mensalmente)

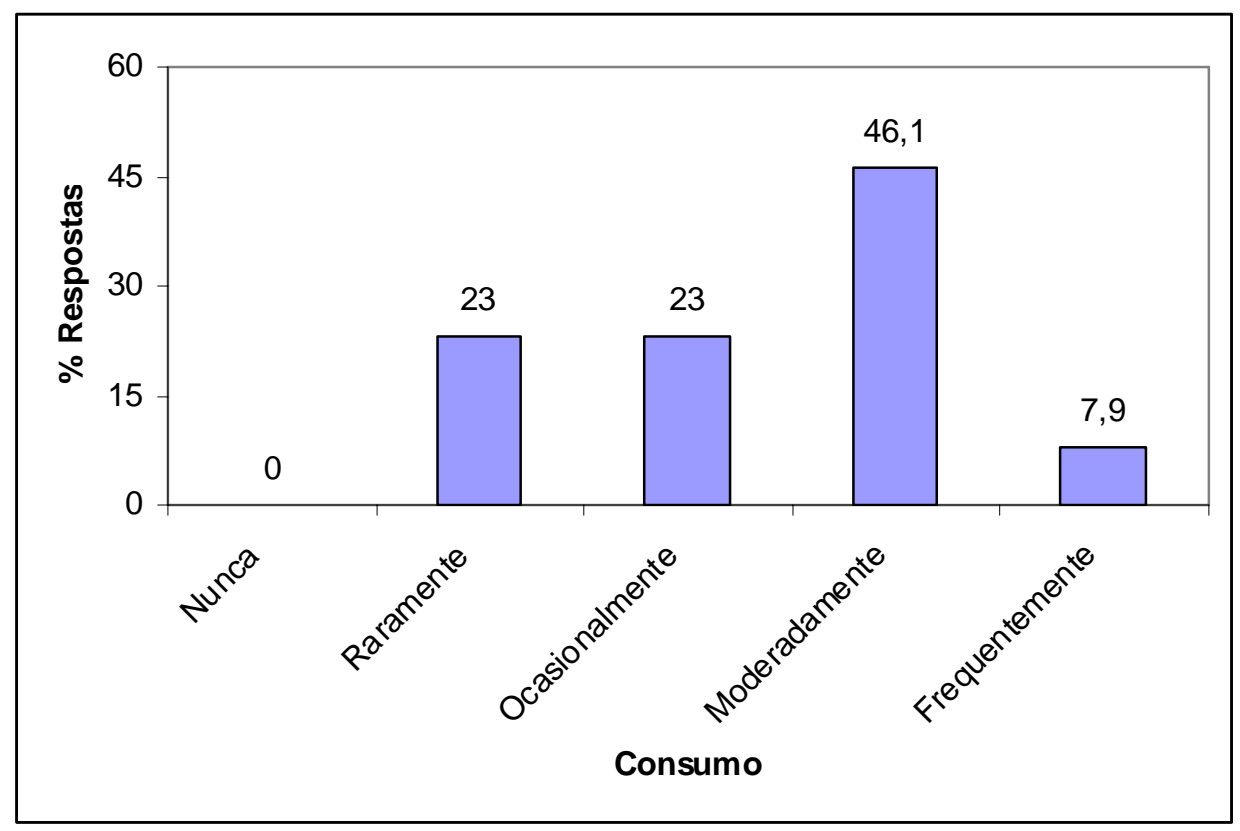

\subsection{Avaliação de aceitação}

\subsubsection{Análise de Variância}

Na Tabela 1 são apresentadas as médias e o desvio padrão dos atributos avaliados no teste de aceitação para as amostras utilizadas.

A análise de variância (ANOVA) e teste de médias de Tukey $(\mathrm{p} \leq 0,05)$ mostrou que as amostras estudadas não apresentaram diferença significativa em relação à cor e aroma. Com relação à aceitação global e a textura todas as amostras diferiram entre si $(\mathrm{p} \leq 0,05)$, tendo a amostra 1 obtido 
Tabela 1. Teste de aceitação das amostras de iogurte adoçado com mel sabor castanha

\begin{tabular}{cccc}
\hline Amostras & $\mathbf{1}$ & $\mathbf{2}$ & $\mathbf{3}$ \\
Atributos & & & \\
\hline Aparência & $6,88 \pm 1,74^{\mathrm{a}}$ & $6,20 \pm 1,70^{\mathrm{a}}$ & $5,34 \pm 2,20^{\mathrm{b}}$ \\
Cor & $6,70 \pm 1,59^{\mathrm{a}}$ & $6,68 \pm 1,58^{\mathrm{a}}$ & $6,00 \pm 2,06^{\mathrm{a}}$ \\
Ac.Global & $7,08 \pm 1,28^{\mathrm{a}}$ & $6,43 \pm 1,34^{\mathrm{b}}$ & $5,28 \pm 2,09^{\mathrm{c}}$ \\
Aroma & $6,85 \pm 1,39^{\mathrm{b}}$ & $6,59 \pm 1,79^{\mathrm{b}}$ & $6,26 \pm 1,93^{\mathrm{b}}$ \\
Sabor & $7,08 \pm 1,56^{\mathrm{a}}$ & $6,62 \pm 1,60^{\mathrm{a}}$ & $5,67 \pm 2,09^{\mathrm{b}}$ \\
Textura & $7,33 \pm 1,47^{\mathrm{a}}$ & $5,62 \pm 1,74^{\mathrm{b}}$ & $4,41 \pm 2,12^{\mathrm{c}}$ \\
\hline
\end{tabular}

${ }^{\text {a, b, c }}$ Médias com letras iguais, em mesma linha, não diferem entre si estatisticamente ao nível de $5 \%$ de significância

maiores médias. Isso pode ser explicado pela influência que o tamanho dos grânulos de castanha exerce sobre a aceitação global, sendo que quanto menor o tamanho dos grânulos (textura mais homogênea) maior a aceitação. Pode-se ainda observar que a amostra de iogurte de castanha batida por $1 / 2$ minuto (amostra 3) diferiu das demais amostras em relação à aparência e sabor, provavelmente devido à presença de pedaços de castanha. As médias obtidas pela amostra 1 foram superiores a 6 , o que representa um valor considerável.

\subsubsection{Análise tabular e gráfica}

Na Tabela 2, encontra-se os percentuais correspondentes as faixas de aceitação, indiferença e rejeição da escala.

Tabela 2. Freqüência Acumulada por atributo do grau de satisfação dos provadores em relação as amostras

\begin{tabular}{c|ccc|ccc|ccc}
\hline \multirow{3}{*}{ Atributos } & \multicolumn{3}{|c|}{ Aceitação ( 6-9 ) } & \multicolumn{3}{c|}{ Indiferença ( 5 ) } & \multicolumn{3}{c}{ Rejeição ( 1-4 ) } \\
\cline { 2 - 10 } & $\mathbf{1}$ & $\mathbf{2}$ & $\mathbf{3}$ & $\mathbf{1}$ & $\mathbf{2}$ & $\mathbf{3}$ & $\mathbf{1}$ & $\mathbf{2}$ & $\mathbf{3}$ \\
\hline Aparência & 82,50 & 75,00 & 47,50 & 7,50 & 7,50 & 7,50 & 10,00 & 17,50 & 45,00 \\
Cor & 77,50 & 70,00 & 60,00 & 17,50 & 20,00 & 15,00 & 8,00 & 10,00 & 25,00 \\
Ac.Global & 91,90 & 81,00 & 55,54 & 5,40 & 13,50 & 5,55 & 2,70 & 5,40 & 38,89 \\
Aroma & 92,34 & 71,79 & 69,22 & 5,13 & 17,95 & 15,38 & 2,56 & 10,25 & 15,37 \\
Sabor & 89,75 & 74,36 & 56,41 & 2,56 & 17,95 & 12,82 & 7,69 & 7,69 & 30,77 \\
Textura & 84,62 & 61,55 & 38,46 & 7,69 & 10,26 & 12,82 & 7,69 & 28,20 & 48,71 \\
\hline
\end{tabular}

A amostra 1 apresentou os maiores percentuais na faixa de aceitação em todos os atributos. Já a amostra 3 foi a mais rejeitada em todos os atributos por obter as maiores freqüências acumuladas nessa faixa da escala.

A Figura 2 representa os resultados obtidos para avaliação da aceitação para aparência e a Figura 3 para cor.

Como os maiores valores da escala hedônica (6-9) equivalem a gostar da amostra, pode-se notar que em relação à avaliação da aceitação do atributo aparência a amostra 1 foi a que obteve maior freqüência hedônica (8), que se refere na escala a "gostei muito". Para avaliação da aceitação pela cor houve um destaque maior para a amostra 2, pelo seu maior número de julgamentos referente também a nota ( $8=$ gostei muito). 
FIGURA 2. Freqüência das notas da escala hedônica para aparência das amostras 1,2 e 3

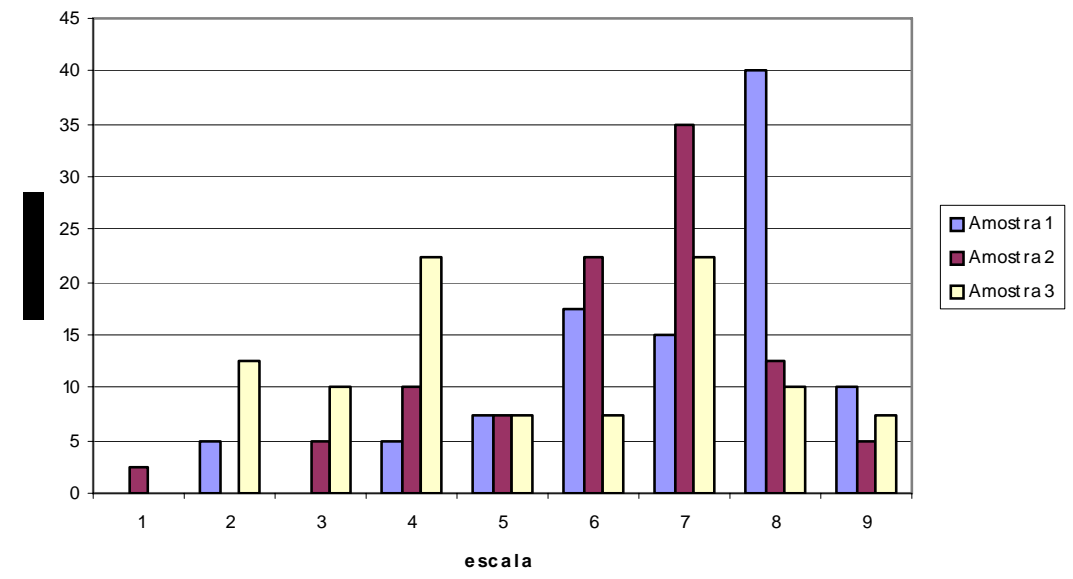

FIGURA 3. Freqüência das notas da escala hedônica para cor das amostras 1, 2 e 3

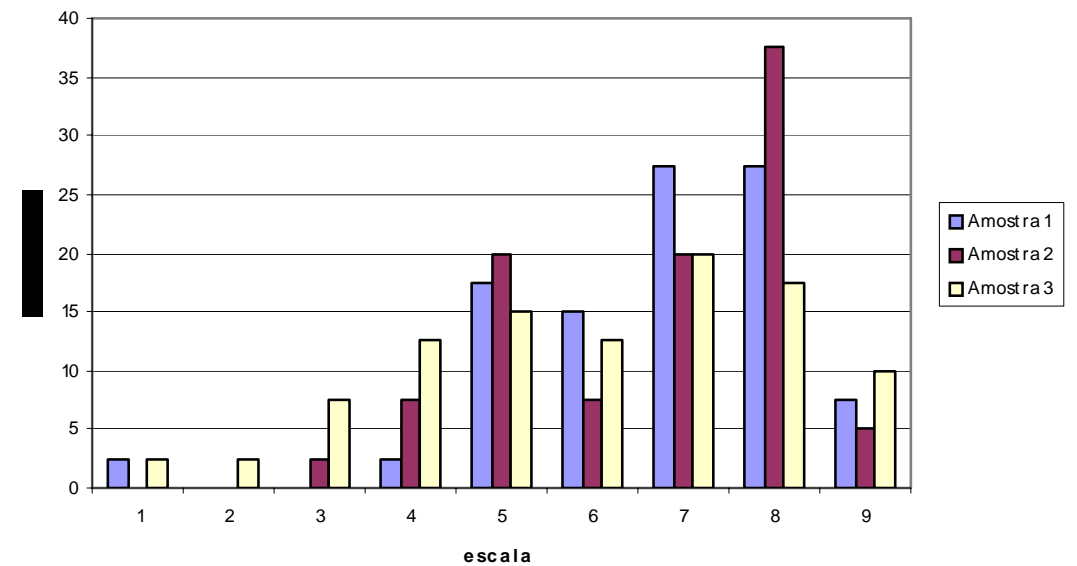

FIGURA 4. Freqüência das notas da escala hedônica para aceitação global das amostras 1, 2 e 3

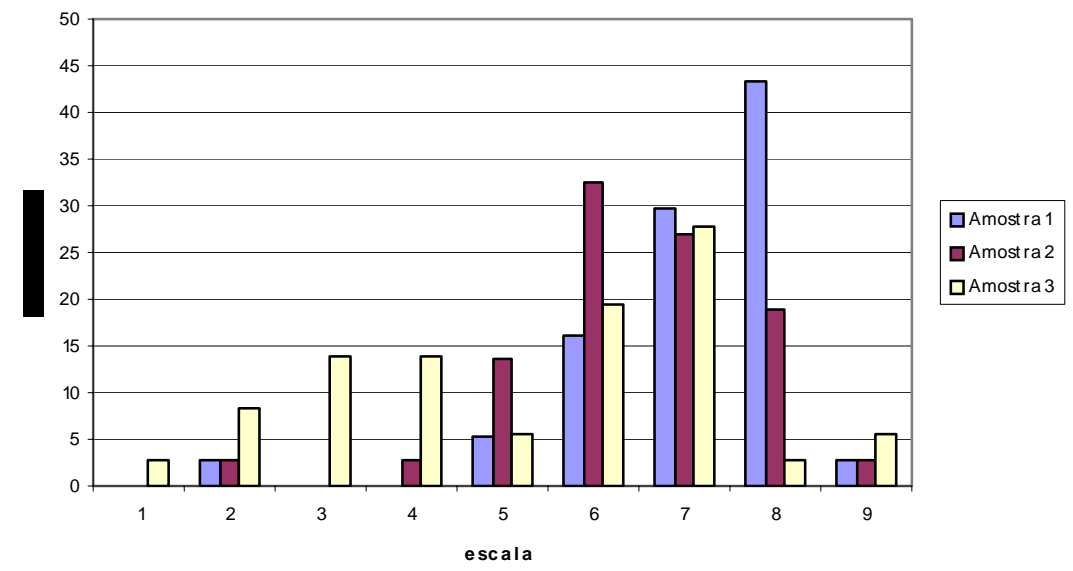

Quanto à aceitação global a amostra 1 apresentou maior freqüência hedônica (8) como mostra a Figura 4 e além disso 91,8\% das respostas ficaram entre os níveis 6 e 9 da escala (Tabela 2), referentes aos graus de gostar. Essa aceitação foi decrescendo da amostra 1 para a 3. Ressaltando 
que o tempo de batimento do iogurte com a castanha foi maior para a amostra 1 e menor para a amostra 3, observa-se que quanto mais batida for a amostra, maior o grau de gostar.

FIGURA 5. Freqüência das notas da escala hedônica para aroma das amostras 1,2 e 3

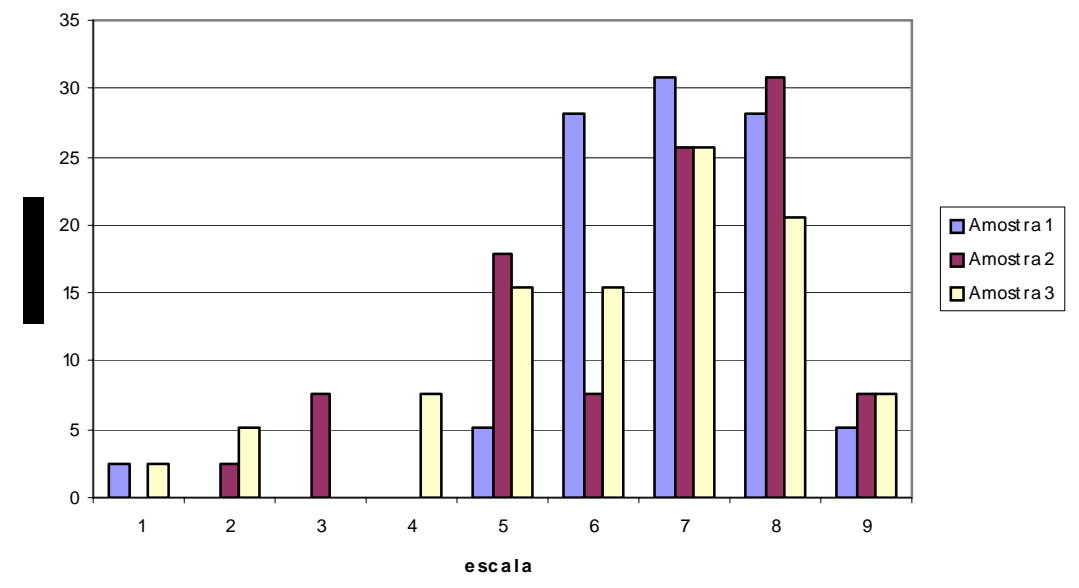

FIGURA 6. Freqüência das notas da escala hedônica para sabor das amostras 1, 2 e 3.

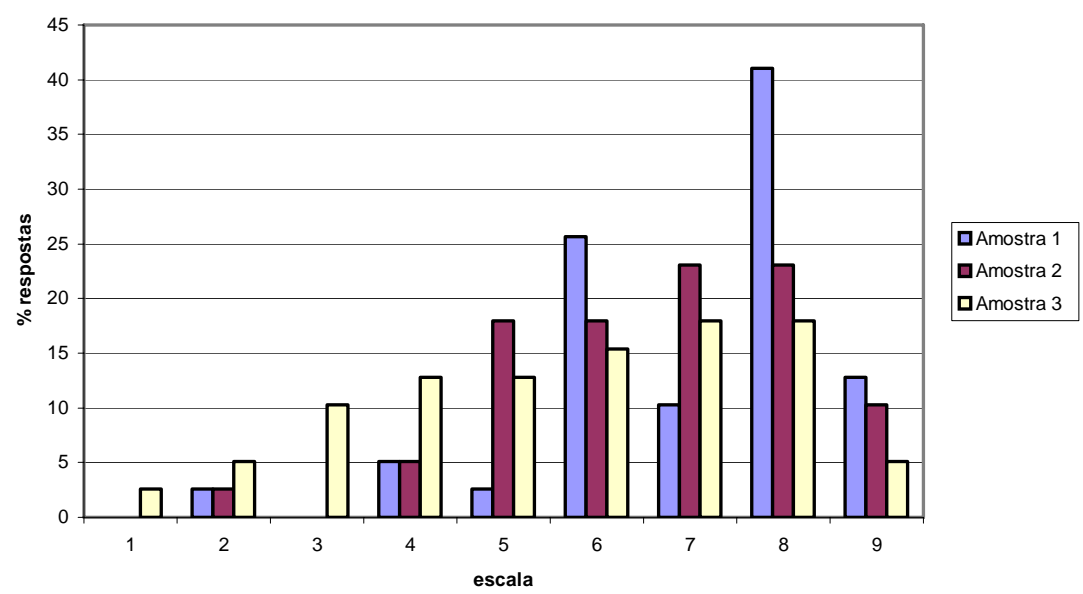

FIGURA 7. Freqüência das notas da escala hedônica para textura das amostras 1,2 e 3 .

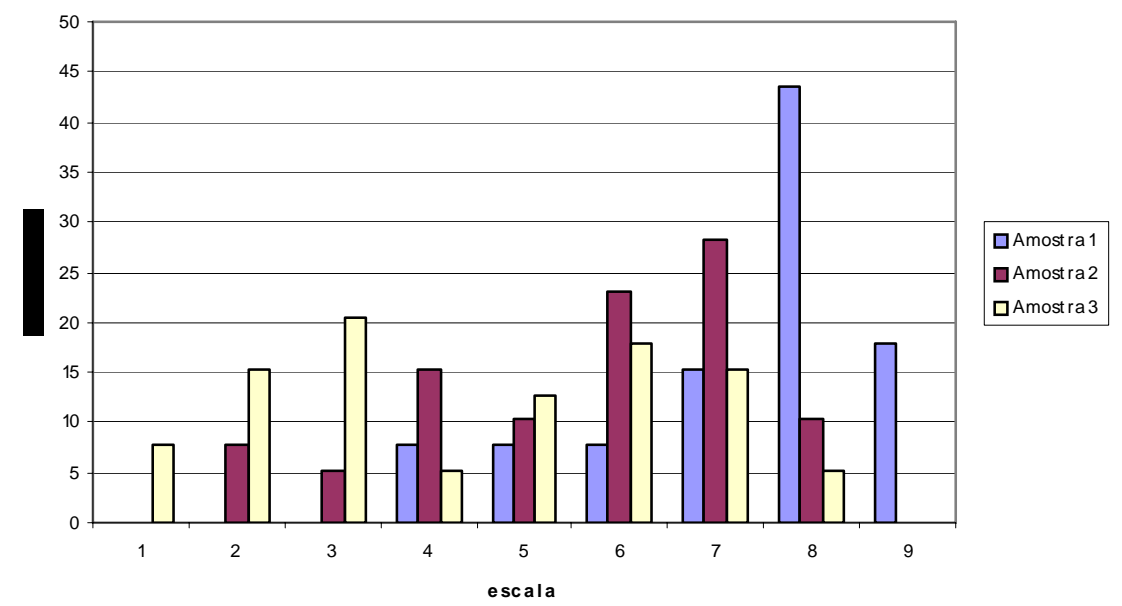


Pode-se observar que em relação à avaliação da aceitação dos atributos aroma, sabor e textura a amostra 1 foi a de maior aceitação, pois apresentou os maiores percentuais de notas na faixa de aceitação da escala. Com relação ao sabor a amostra 1 apresentou maior freqüência hedônica (8) e como pode ser observada na Figura 6, as notas atribuídas pelos provadores são superiores nessa amostra, mostrando que o iogurte de castanha batido por 2 minutos tem o sabor mais apreciado pelos provadores.

$\mathrm{Na}$ avaliação da aceitação da textura foi obtido o menor percentual de notas entre 6 e 9 , sendo este 38,46\% para a amostra 3 (Tabela 2). A amostra 1 apresentou maior freqüência do índice hedônico (8). Com os resultados obtidos, observa-se que o tempo de batimento exerce grande influência na aceitabilidade da textura, sendo esta menor no iogurte batido com a castanha por $1 / 2$ minuto e maior no iogurte batido por 2 minutos.

\subsection{Teste de Diferença do controle}

O teste de diferença do controle permitiu verificar se as amostras de iogurte natural adoçado com mel sabor castanha, diferiam significativamente entre si e da amostra-controle (iogurte natural adoçado com mel) em termos globais.

Os resultados, avaliados através de análise de variância e teste de médias de Dunnett, demonstraram que todas as amostras de iogurte adicionado de castanha diferiam significativamente do controle $(\mathrm{p} \leq 0,05)$. Esta diferença deve-se, provavelmente, à presença de castanha (Tabela 3).

Tabela 3 - Teste de Diferença de Controle das amostras de iogurte adoçado sabor castanha

\begin{tabular}{ccc}
\hline Amostra & Média & Desvio Padrão \\
\hline $\mathbf{1}$ & $5,63^{\mathrm{j}}$ & 1,98 \\
$\mathbf{2}$ & $5,40^{\mathrm{j}}$ & 1,97 \\
$\mathbf{3}$ & $5,25^{\mathrm{j}}$ & 2,35 \\
Controle & $1,08^{\mathrm{m}}$ & 1,61 \\
\hline
\end{tabular}

${ }^{\mathrm{j}, \mathrm{m}}$ Médias com letras iguais na mesma coluna não diferem entre si $(\mathrm{p} \leq 0,05)$

\subsection{Atitude de compra e de consumo}

A Figura 8 representa os resultados obtidos para avaliação da atitude de compra e a Figura 9 para atitude de consumo. 
FIGURA 8 - Freqüência das notas da atitude de compra das amostras 1, 2 e 3

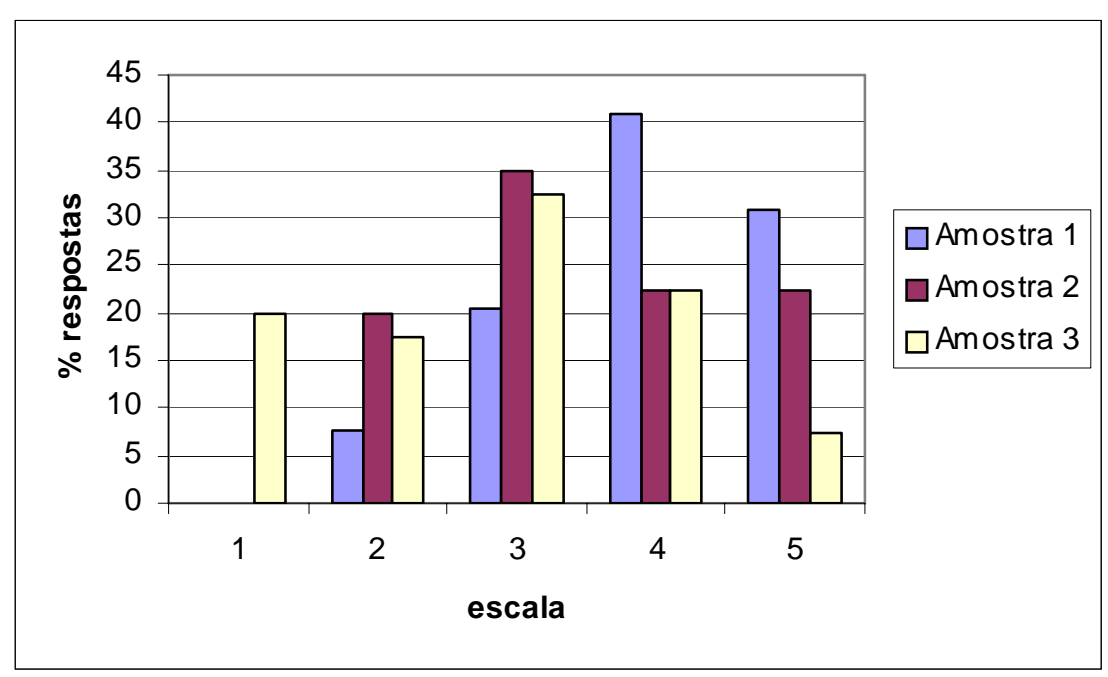

Como os maiores valores da escala de atitude de compra (4-5) equivalem a comprar a amostra, pode-se notar que a amostra 1 obteve maior freqüência nestes valores $(71,8 \%)$, possuindo assim maior potencial de compra, enquanto as amostras 2 e 3 obtiveram apenas 45\% e 30\%, respectivamente. A amostra 1 obteve maior percentual de respostas no nível 4 da escala $(41,03 \%)$ que corresponde a "eu provavelmente compraria". Já as amostras 2 e 3 alcançaram 35\% e 32,5\%, respectivamente, no nível 3 da escala que equivale a "tenho dúvida se compraria".

FIGURA 9 - Freqüência das notas da atitude de consumo das amostras 1, 2 e 3

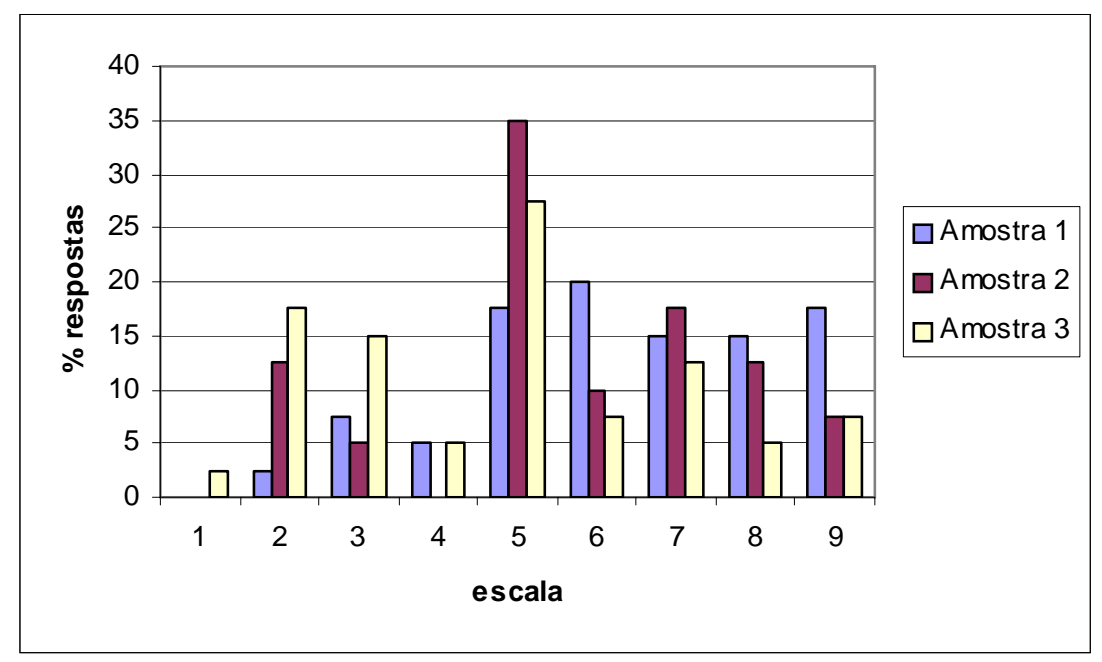

Os níveis de 6-9 da escala representam atitude positiva quanto ao consumo do produto. As amostras 1, 2 e 3 obtiveram nesses níveis um percentual de respostas de 67,5\%, 47,5\% e 32,5\%, respectivamente. Destaque maior deve ser dado à amostra 1 que obteve maior percentual de respostas no nível 6 da escala correspondente a "gosto e comeria de vez em quando". As amostras 2 e 3 alcançaram seu maior percentual de respostas no nível 5 da escala $(35 \%$ e 27,5\%, respectivamente), correspondente a "comeria se estivesse acessível, mas não me esforçaria para isso". 


\subsection{Atributos mais e menos preferidos}

As Figuras de 10 à 15 representam os atributos mais citados como menos e mais preferidos em cada amostra.

FIGURA 10 - Características mais preferidas da Amostra 1 e o percentual de citações

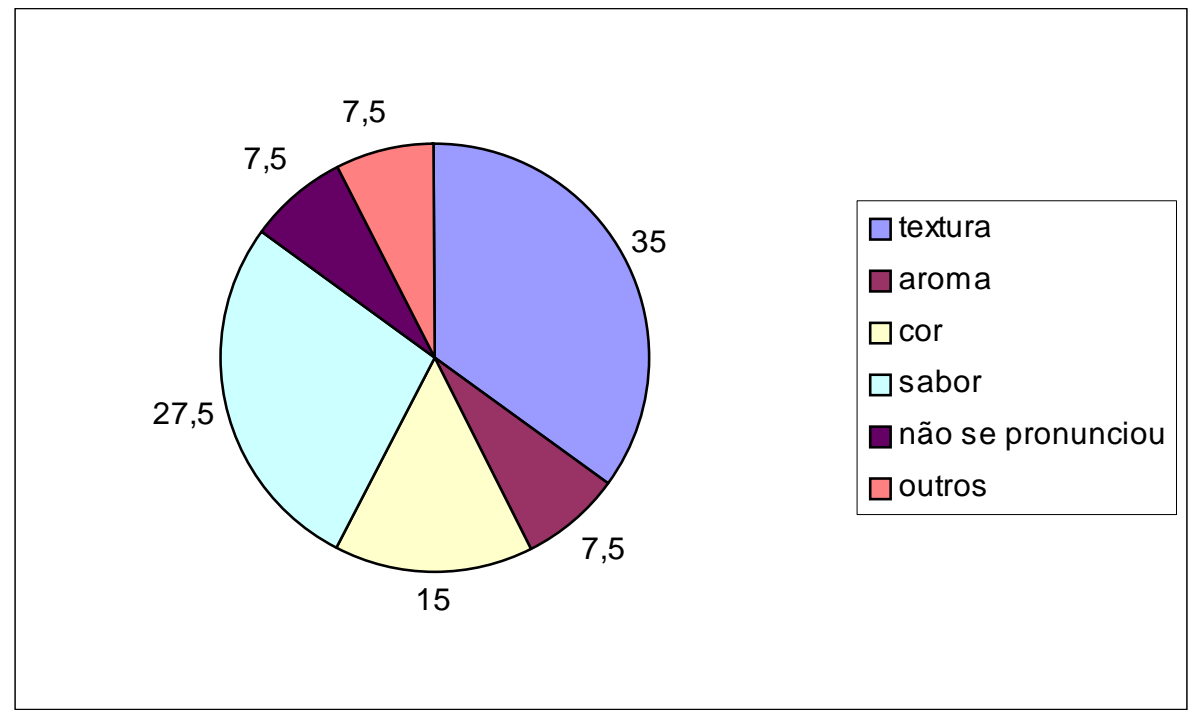

FIGURA 11 - Características menos preferidas da Amostra 1 e o percentual de citações

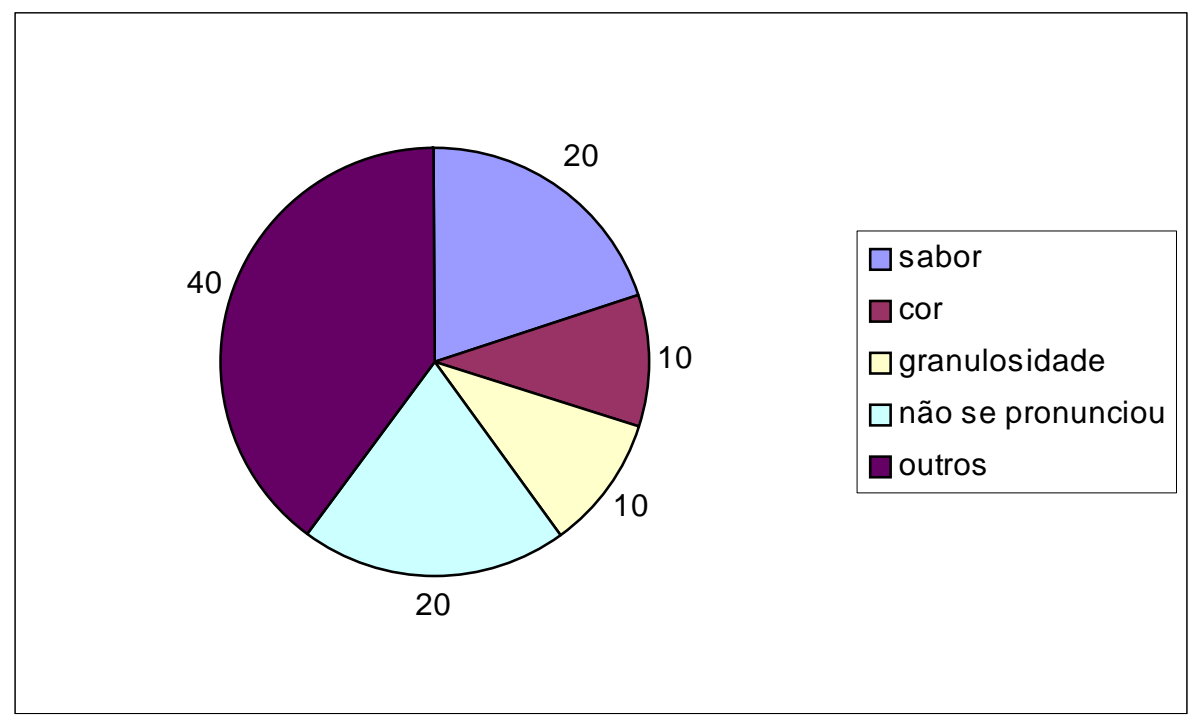

Dentre os atributos citados como mais preferidos da amostra 1 estão textura, sabor e cor que corresponderam, respectivamente, a 35\%, 27,5\% e 15\% das citações. Porém o sabor e a cor também foram citados como características menos preferidas com $20 \%$ e $10 \%$ das citações, respectivamente. Sendo assim, verificamos que o atributo mais preferido pelos provadores foi a textura. Como na amostra 1 a castanha foi batida por mais tempo com o iogurte ( 2 minutos), essa amostra tem uma textura mais fina que a das demais. Porém um aspecto da textura foi citado como menos preferido, a granulosidade, mesmo sendo esta menor na amostra 1. 
FIGURA 12 - Características mais preferidas da Amostra 2 e o percentual de citações

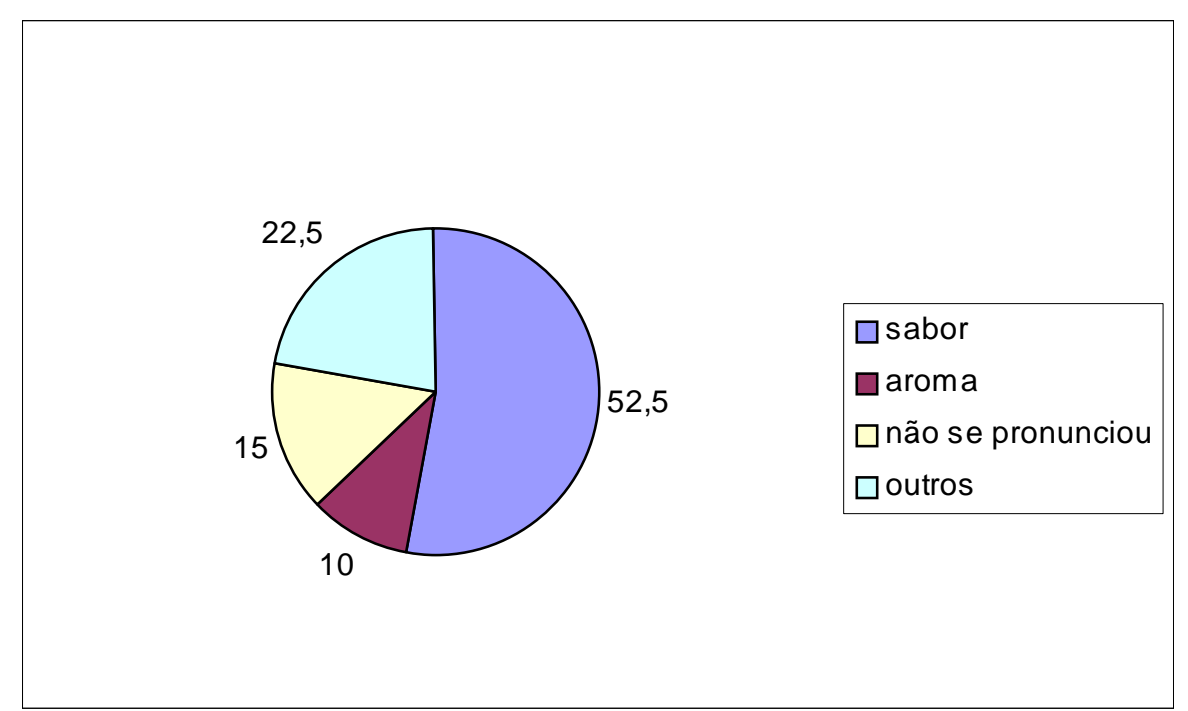

FIGURA 13 - Características menos preferidas da Amostra 2 e o percentual de citações

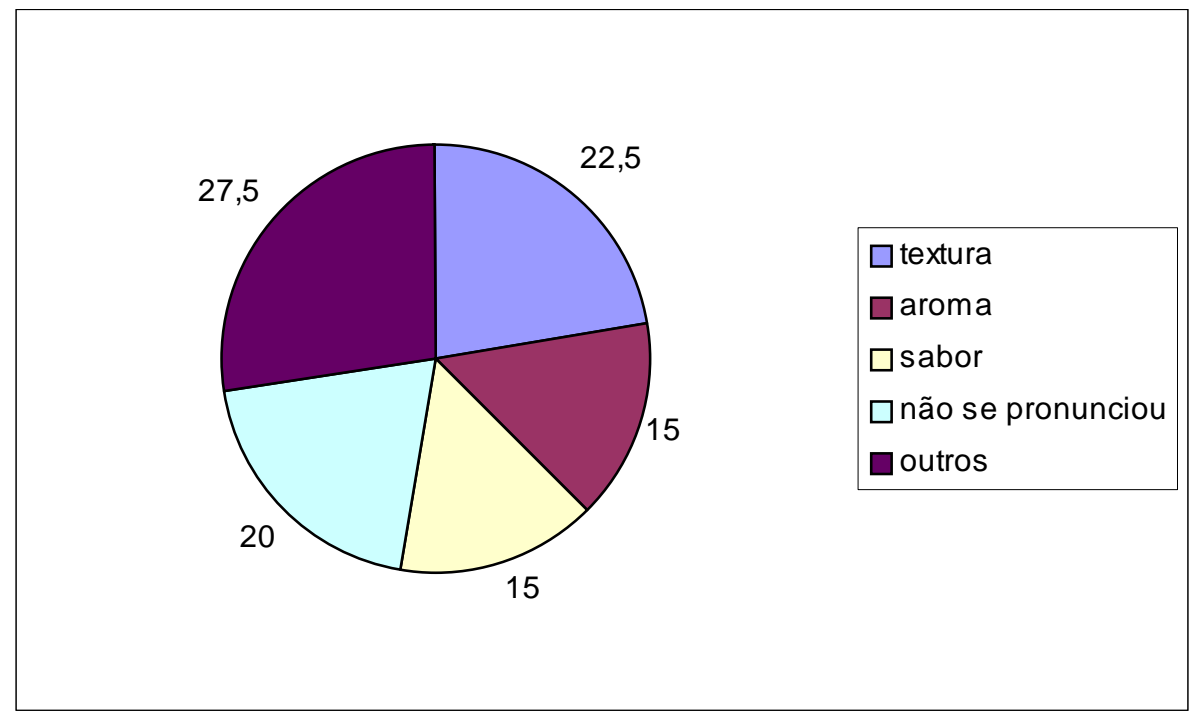

O atributo sabor obteve $52,5 \%$ de citações como o mais preferido na amostra 2. Dentre os menos preferidos foram citados textura, aroma e sabor com 22,5\%, 15\% e 15\% de citações, respectivamente. Diante disso, verificamos que o sabor foi o atributo mais preferido pela maioria dos provadores e a textura o atributo menos preferido. Como a amostra 2 foi batida por um tempo menor ( 1 minuto) que a amostra 1 ( 2 minutos), a granulosidade desta é maior. 
FIGURA 14 - Características mais preferidas da Amostra 3 e o percentual de citações

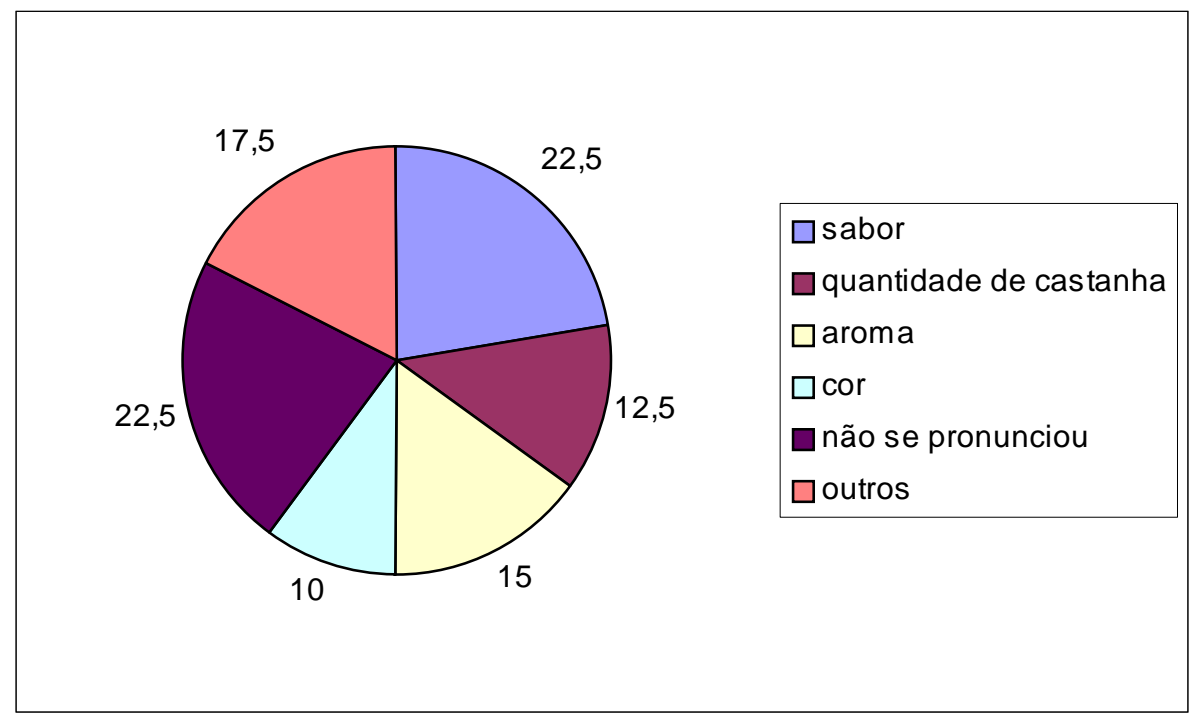

FIGURA 15 - Características menos preferidas da Amostra 3 e o percentual de citações

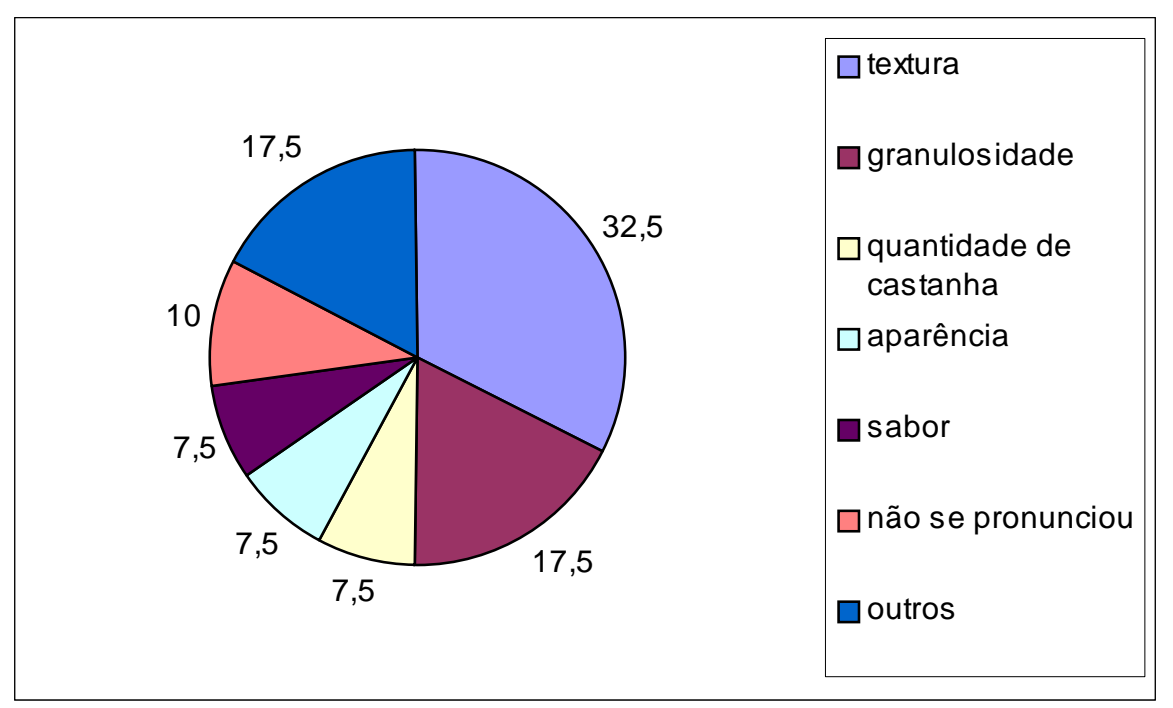

A amostra 3 teve o sabor como atributo mais preferido com um percentual de citações de $22,5 \%$ mesmo este também tendo sido citado como menos preferido (7,5\%). As características mais citadas como menos preferidas foram a textura e a granulosidade com 32,5\% e 17,5\% de citações, respectivamente. Esta amostra foi batida apenas por $1 / 2$ minuto, portanto é a amostra que apresenta textura mais grossa devido a granulosidade ser maior que nas demais amostras. Esse resultado mostra que quanto maior a granulosidade menos preferida é a amostra.

\section{Conclusão}

Não houve diferença significativa $(\mathrm{p} \leq 0,05)$ entre as amostras nos atributos cor e aroma, já na aceitação global e na textura todas as amostras diferiram entre si. Nos atributos aparência e sabor apenas a amostra 3 (batida por $1 / 2$ minuto) diferiu das demais. 
As amostras de iogurte de castanha apresentaram ótima aceitação, onde a amostra 1 (batida por 2 minutos) obteve um maior destaque, sendo a mais apreciada em aparência, aceitação global, aroma, sabor e textura. Já no atributo cor, a amostra 2 (batida por 1 minuto) prevaleceu.

A textura exerceu influência na aceitação global, pois a aceitação desses atributos foi decrescente da amostra 1 para a amostra 3, ou seja, da amostra de menor granulosidade (homogeneidade) para a de maior.

As amostras de iogurte de castanha apresentaram bom potencial de consumo e de compra. Destaque maior para a amostra 1 com um elevado pontecial.

Constatou-se que todas as amostras apresentam diferença significativa quando comparadas com o padrão $(\mathrm{p} \leq 0,05)$ em termos globais.

A amostra 1 teve a textura como atributo mais preferido, sendo esta a amostra de textura mais fina e homogênea. A amostra 3 teve a textura e a granulosidade como características menos preferidas, mostrando que um menor tamanho dos grânulos de castanha e uma textura mais homogênea tem maior aceitação pelo consumidor.

Portanto, o iogurte adoçado com mel sabor castanha, possivelmente, ocuparia um bom espaço no mercado.

\begin{abstract}
The yoghurt is a product resulting from the fermentation of pasteurized milk, by lactic ferments. In recent years, the food industry has launched several products to gain market, mainly due to changes in consumer preferences. Thus, the study aims to develop and evaluate the sensory properties of three prototypes of natural yoghurt sweetened (NYS) with honey chestnut flavor (decoded into 1, 2 and 3), differentiated in relation to the time of the almond mixture of cashew nuts with the yogurt. The raw materials commercial used were: NYS with $1 \%$ of honey and the almonds cashew nuts into pieces. A scale structured for five-point was used to evaluate the attitude of buying and three scales in nine points: a scale hedonic, one for analysis of difference in control and other to assess the attitude of consumption. Participated of tests 40 tasters no trained. The sample 1 showed a high potential for purchase, consumption, was the most preferred in appearance, overall acceptability, aroma, flavor and texture. The sample 3 had the texture and granularity characteristics as less preferred, showing that a more homogeneous texture have greater acceptance by consumers. Already in the attribute color, the sample 2 was the highest preference. The test of difference from control showed that the samples added of cashew nuts differ $(p<0,05)$ in terms overall of the control sample. So the yogurt sweetened with honey flavor chestnut, possibly occupy in a good space market.
\end{abstract}

Key-words: almonds cashew chestnut, yoghurt, sensorial analysis.

\title{
5. Referências
}

BRASIL. Resolução No 5, de 13 de novembro de 2000. Padrões de Identidade e Qualidade (PIQ) de Leites Fermentados. Diário Oficial da União, Brasília, DF, 27 nov. 2000, seção 1, p. 9. 
CAJUCUltura. Produtos e Derivados do Cajueiro, disponível em $<$ http://cajucultura.com.br/derivados /derivados.html.html>, acesso em 7/02/2009.

CHITARRA, M. I. F.; CHITARRA, A. B. Pós-colheita de Frutas e Hortaliças - Glossário. Lavras, MG: UFLA, 2006.

DUTCOSKY, S. D. Análise Sensorial de Alimentos. Curitiba: CHAMPAGNAT, 2 ed. 2007.

MEILGAARD, M.; CIVILLE, C. Sensory Evalution Techniques. New York : Boca Raton, 3 ed. 1999.

MOnTGomery, D. C.; RUnGeR, G. C. Estatística Aplicada e Probabilidade para Engenheiros, 2 ed. Rio de Janeiro, RJ: LTC, 2003.

ORDONEZ, J. A. Tecnologia de alimentos - Alimentos de origem animal, v. 2. Porto Alegre, RS: Artmed, 2005.

PEINADO, J.; GRAEML, A. R. Administração da Produção (Operações Industriais e de Serviços). Curitiba, PR: UnicenP, 2007).

SILVA, J. A. Tópicos da Tecnologia de Alimentos. São Paulo, SP: Varela, 2000.

TAMIME, A. Y.; ROBINSON, R. K. YOGHURT Science and Technology, 2 ed. England: Woodhead Publishing Limited, 2000.

Nome completo: Jéfferson Malveira Cavalcante; Ana Cristina da Silva Morais; *Maria do Carmo Passos Rodrigues.

Filiação institucional: Universidade Federal do Ceará - UFC.

Departamento: Departamento de Tecnologia de Alimentos - DETAL (Laboratório de Análise Sensorial)

Função ou cargo ocupado: Alunos de pós-graduação; *docente.

Endereço para correspondência: Avenida Mister Hull, 2977 Bloco 857 Alagadiço Fortaleza, CE Brasil Caixa Postal: 12168 CEP: 60356-000

Telefones para contato: (85) 3366-9741

e-mail: jmalveirac@gmail.com 